\title{
Variable ventilation improves pulmonary function and reduces lung damage without increasing bacterial translocation in a rat model of experimental pneumonia
}

Raquel F. de Magalhães ${ }^{1}$, Cynthia S. Samary ${ }^{1}$, Raquel S. Santos ${ }^{1}$, Milena V. de Oliveira', Nazareth N. Rocha', Cintia L. Santos ${ }^{1}$, Jamil Kitoko ${ }^{1}$, Carlos A. M. Silva ${ }^{5}$, Caroline L. Hildebrandt',

Cassiano F. Goncalves-de-Albuquerque ${ }^{5}$, Adriana R. Silva ${ }^{5}$, Hugo C. Faria-Neto ${ }^{5}$, Vanessa Martins ${ }^{6}$, Vera L. Capelozzi ${ }^{6}$, Robert Huhle ${ }^{7}$, Marcelo M. Morales ${ }^{2}$, Priscilla Olsen ${ }^{3,4}$, Paolo Pelosi ${ }^{8}$, Marcelo Gama de Abreu ${ }^{7}$, Patricia R. M. Rocco ${ }^{1}$ and Pedro L. Silva ${ }^{1,9^{*}}$

\begin{abstract}
Background: Variable ventilation has been shown to improve pulmonary function and reduce lung damage in different models of acute respiratory distress syndrome. Nevertheless, variable ventilation has not been tested during pneumonia. Theoretically, periodic increases in tidal volume $\left(V_{T}\right)$ and airway pressures might worsen the impairment of alveolar barrier function usually seen in pneumonia and could increase bacterial translocation into the bloodstream. We investigated the impact of variable ventilation on lung function and histologic damage, as well as markers of lung inflammation, epithelial and endothelial cell damage, and alveolar stress, and bacterial translocation in experimental pneumonia.
\end{abstract}

Methods: Thirty-two Wistar rats were randomly assigned to receive intratracheal of Pseudomonas aeruginosa (PA) or saline (SAL) ( $n=16 /$ group). After 24-h, animals were anesthetized and ventilated for $2 \mathrm{~h}$ with either conventional volume-controlled $(\mathrm{VCV})$ or variable volume-controlled ventilation $(\mathrm{W})$, with mean $\mathrm{V}_{\mathrm{T}}=6 \mathrm{~mL} / \mathrm{kg}, \mathrm{PEEP}=5 \mathrm{cmH}_{2} \mathrm{O}$, and $\mathrm{FiO}_{2}=0.4$. During $W$, tidal volume varied randomly with a coefficient of variation of $30 \%$ and a Gaussian distribution. Additional animals assigned to receive either PA or SAL ( $n=8 /$ group) were not ventilated (NV) to serve as controls.

(Continued on next page)

\footnotetext{
* Correspondence: pedro.leme@gmail.com

'Laboratory of Pulmonary Investigation, Carlos Chagas Filho Biophysics Institute, Federal University of Rio de Janeiro, Av. Carlos Chagas Filho, $s / \mathrm{n}$, Bloco G-014, Ilha do Fundão, 21941-902 Rio de Janeiro, RJ, Brazil

'Laboratory of Pulmonary Investigation, Centro de Ciências da Saúde, Carlos

Chagas Filho Biophysics Institute, Federal University of Rio de Janeiro,

Avenida Carlos Chagas Filho, s/n, Bloco G-014, Ilha do Fundão, 21941-902 Rio

de Janeiro, RJ, Brazil

Full list of author information is available at the end of the article
} 
(Continued from previous page)

Results: In both SAL and PA, W improved oxygenation and lung elastance compared to VCV. In SAL, W decreased interleukin (IL)-6 expression compared to VCV (median [interquartile range]: 1.3 [0.3-2.3] vs. 5.3 [3.6-7.0]; $p=0.02$ ) and increased surfactant protein-D expression compared to NV (2.5 [1.9-3.5] vs. 1.2 [0.8-1.2]; $p=0.0005)$. In PA, compared to VCV, W reduced perivascular edema (2.5 [2.0-3.75] vs. 6.0 [4.5-6.0]; $p<0.0001$ ), septum neutrophils (2. 0 [1.0-4.0] vs. $5.0[3.3-6.0] ; p=0.0008$ ), necrotizing vasculitis (3.0 [2.0-5.5] vs. 6.0 [6.0-6.0]; $p=0.0003$ ), and ultrastructural lung damage scores (16 [14-17] vs. 24 [14-27], $p<0.0001)$. Blood colony-forming-unit (CFU) counts were comparable (7 [0-28] vs. 6 [0-26], $p=0.77)$. Compared to NV, VCV, but not W, increased expression amphiregulin, IL-6, and cytokine-induced neutrophil chemoattractant (CINC)-1 (2.1 [1.6-2.5] vs. 0.9 [0.7-1.2], $p=0$. $025 ; 12.3[7.9-22.0]$ vs. $0.8[0.6-1.9], p=0.006$; and 4.4 [2.9-5.6] vs. $0.9[0.8-1.4], p=0.003$, respectively). Angiopoietin2 expression was lower in $\mathrm{W}$ compared to NV animals (0.5 [0.3-0.8] vs. $1.3[1.0-1.5], p=0.01)$.

Conclusion: In this rat model of pneumonia, $\mathrm{W}$ improved pulmonary function and reduced lung damage as compared to VCV, without increasing bacterial translocation.

Keywords: Pneumonia, Variable ventilation, Lung mechanics, Lung damage, Inflammation, Molecular biology

\section{Background}

Despite advances in medical care, the prevalence and mortality rates of pneumonia remain relatively high [1]. The cornerstone of pneumonia treatment is antibiotic therapy. However, patients may also require mechanical ventilation to maintain adequate gas exchange and reduce the work of breathing. In fact, pneumonia is a major risk factor for the acute respiratory distress syndrome (ARDS) [2], for which protective ventilation with low tidal volumes has been advocated [3]. However, overdistension and cyclic opening and closure of alveolar units, two of the major mechanisms of ventilatorinduced lung injury (VILI), may occur even during protective lung ventilation [4-6].

The use of variable tidal volumes, i.e., variable ventilation, has been shown to improve pulmonary function and reduce lung damage in different experimental models of direct [7-9] and indirect [8, 10] ARDS. Nevertheless, variable ventilation has not been tested during pneumonia. Theoretically, periodic increases in tidal volume $\left(\mathrm{V}_{\mathrm{T}}\right)$ and airway pressures might worsen the impairment of alveolar barrier function usually seen in pneumonia [11], and could increase bacterial translocation into the bloodstream [12, 13]. On the other hand, since variable ventilation can recruit the lungs [10] and thereby decrease regional stress and strain, a protective effect against lung damage and bacterial translocation might result.

In the present study, we investigated the impact of variable ventilation on respiratory mechanics, gas exchange, and lung histologic damage, as well as markers of lung inflammation, epithelial and endothelial cell damage, and alveolar stress, in a rat model of pneumonia induced by Pseudomonas aeruginosa. We hypothesized that variable ventilation would improve pulmonary function and reduce lung damage without increasing bacterial translocation.

\section{Methods}

\section{Animal preparation and experimental protocol}

Thirty-two Wistar rats (weight, 300-410 g) were anesthetized under spontaneous breathing with $2 \%$ isoflurane (Isoforine; Cristália, Itapira, SP, Brazil) and randomly assigned to two groups: 1) Pneumonia (PA, $n=16$ ), in which Pseudomonas aeruginosa 01 (ATCC27853, $5 \times$ $10^{7} \mathrm{CFU}$ diluted in $200 \mu \mathrm{L}$ saline) was instilled intratracheally (i.t.) (see Additional file 1 for details of the development of the pneumonia model); and 2) Control, in which $200 \mu \mathrm{L}$ saline was instilled i.t. (SAL, $n=16$ ). Eight animals in the SAL and PA groups were not ventilated (NV) and served as controls for computation of lung damage score, ultrastructural damage score, and molecular biology analyses. After $24 \mathrm{~h}$, animals were premedicated intraperitoneally (i.p.) with $10 \mathrm{mg} / \mathrm{kg}$ diazepam (Compaz, Cristália, Itapira, SP, Brazil), followed by $100 \mathrm{mg} / \mathrm{kg}$ ketamine (Ketamin-S+, Cristália, Itapira, SP, Brazil) and $2 \mathrm{mg} / \mathrm{kg}$ midazolam (Dormicum, União Química, São Paulo, SP, Brazil). An intravenous (i.v.) catheter (Jelco 24G, Becton, Dickinson and Company, New Jersey, NJ, USA) was inserted into the tail vein, and anesthesia induced and maintained with midazolam $(2 \mathrm{mg} / \mathrm{kg} / \mathrm{h})$ and ketamine $(50 \mathrm{mg} / \mathrm{kg} / \mathrm{h})$. Following local anesthesia with $2 \%$ lidocaine $(0.4 \mathrm{ml})$, a midline neck incision and tracheostomy were performed. A second catheter (PE-50, Becton, Dickinson and Company) was then placed in the right internal carotid artery for blood sampling and gas analysis (Radiometer ABL80 FLEX, Copenhagen NV, Denmark), as well as monitoring of mean arterial pressure (MAP) (Networked Multiparameter Veterinary Monitor LifeWindow 6000 V; Digicare Animal Health, Boynton Beach, FL, USA). A 30-cm-long water-filled catheter (PE-205, Becton, Dickinson and Company) with side holes at the tip, connected to a differential pressure transducer (UT-PL-400, SCIREQ, Montreal, QC, Canada), was used to measure the esophageal pressure (Pes). The catheter was passed into the stomach 
and then slowly returned into the esophagus; its proper positioning was assessed with the "occlusion test" [14]. Animals were then paralyzed with $2 \mathrm{mg} / \mathrm{kg}$ pancuronium bromide i.v. (Cristália, Itapira, SP, Brazil), and lungs mechanically ventilated (Inspira, Harvard Apparatus, Holliston, MA, USA) in volume-controlled ventilation (VCV) mode with $\mathrm{V}_{\mathrm{T}}=6 \mathrm{~mL} / \mathrm{kg}$, respiratory rate $=80$ breaths $/$ min, $\mathrm{FiO}_{2}=0.4$, and positive end-expiratory pressure $(\mathrm{PEEP})=5 \mathrm{cmH}_{2} \mathrm{O}$. Arterial blood gases and lung mechanics were analyzed (Baseline). SAL and PA groups were then randomly assigned to $2 \mathrm{~h}$ of conventional VCV or variable VCV (VV). Conventional ventilation settings were similar to those previously applied $\left(\mathrm{V}_{\mathrm{T}}=6 \mathrm{~mL} / \mathrm{kg}\right.$, respiratory rate $=80$ breaths $/ \mathrm{min}, \mathrm{FiO}_{2}=0.4$, and $\mathrm{PEEP}=5 \mathrm{cmH}_{2} \mathrm{O}$ ). At the end of the experiments (End), arterial blood gases were measured and $20 \mu \mathrm{L}$ of peripheral blood was sampled for bacterial counts. Animals were killed by exsanguination through the arterial line, and their lungs extracted at $\mathrm{PEEP}=5 \mathrm{cmH}_{2} \mathrm{O}$ for light microscopy and molecular biology analyses.

\section{Variable ventilation}

Variable ventilation was applied as described in detail elsewhere $[15,16]$ Briefly, a sequence of randomly generated $V_{T}$ values (normal distribution, mean $=6 \mathrm{~mL} / \mathrm{kg}$, coefficient of variation $[\mathrm{CV}]=30 \%, n=600)$ was applied in volumecontrolled mode using a routine developed by our group (nVentInspira, Dresden, Germany). The sequence continuously looped itself until the end of the experiments. All other mechanical ventilator settings were kept unchanged: mean $\mathrm{V}_{\mathrm{T}}=6 \mathrm{~mL} / \mathrm{kg}$, respiratory rate $=80$ breaths $/ \mathrm{min}, \mathrm{FiO}_{2}=0.4$, and $\mathrm{PEEP}=5 \mathrm{cmH}_{2} \mathrm{O}$. Figure 1 depicts representative tracings of airflow, volume, and airway pressure (Paw) during conventional ventilation (VCV, left column) and variable ventilation (VV, right column).

\section{Lung mechanics}

Airflow $(\dot{V})$, as well as Paw and esophageal pressure (Pes) were continuously recorded throughout the experiments with a computer running customer-made software written in LabVIEW (National Instruments, Austin, TX) [17]. $V_{T}$ was calculated by digital integration of $\dot{V}$. All signals were amplified in a four-channel signal conditioner (SC-24, SCIREQ, Montreal, QC, Canada). The mechanical properties of the lungs, namely elastance $\left(\mathrm{E}_{\mathrm{L}}\right)$ and resistance $\left(R_{L}\right)$, were calculated by fitting the signals to the equation of motion, according to transpulmonary pressure $\left(\mathrm{P}_{\mathrm{L}}=\right.$ Paw-Pes), as shown in Equation 1:

$$
P_{L}(t)=R_{L} \cdot \dot{V}(t)+E_{L} \bullet V(t)+P_{0, L}
$$

where $\mathrm{P}_{0, \mathrm{~L}}$ is $\mathrm{P}_{\mathrm{L}}$ at end expiration.

\section{Lung damage score}

The left lung was removed, fixed, and embedded in paraffin. Sections $(4 \mu \mathrm{m}$ thick) were cut and stained with hematoxylin and eosin. A lung damage score based on features commonly seen in pneumonia models was computed [18]. For this purpose, the following histological features were analyzed in the tissue sections: perivascular edema, septal neutrophils, and necrotizing vasculitis.
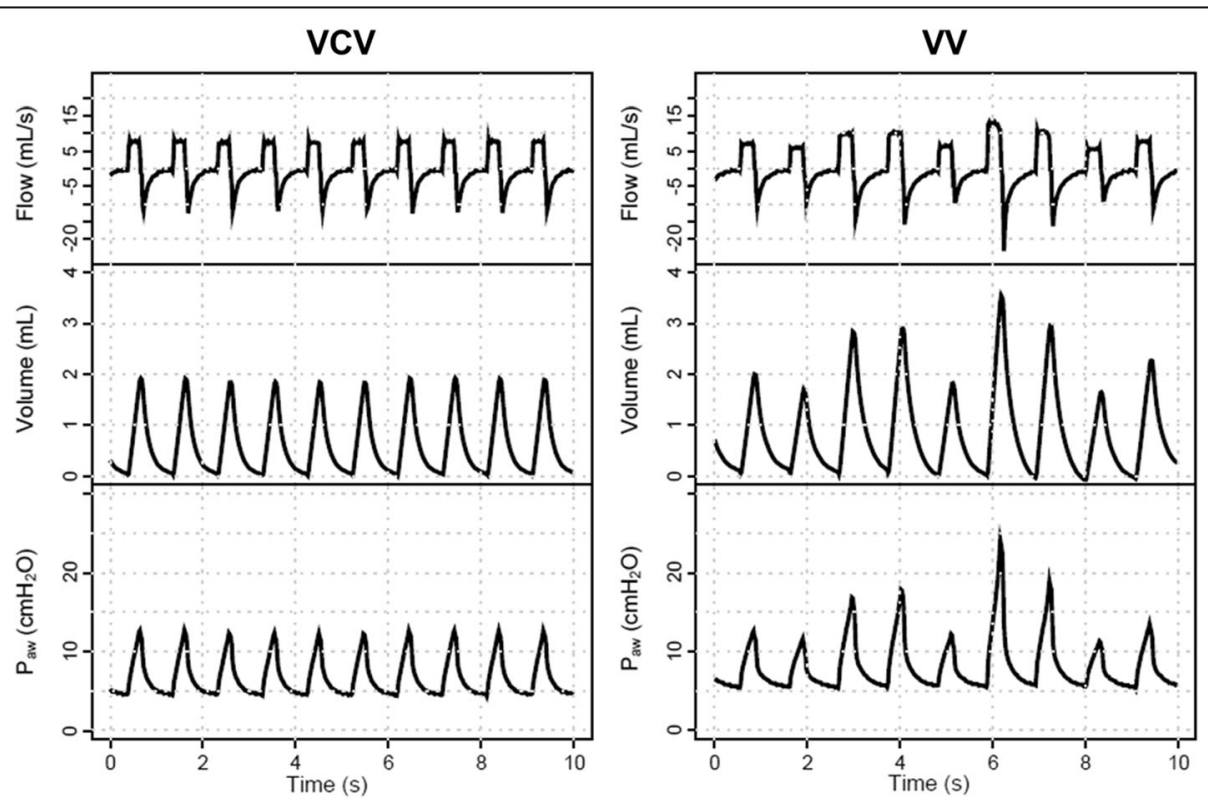

Fig. 1 Representative tracings of airway flow, volume, and pressure $\left(\mathrm{P}_{\text {aww }}\right)$ during volume controlled ventilation (VCV, left column) and variable volume-controlled ventilation ( $\mathrm{W}$, right column) 
Each feature was scored according to severity, with 0 denoting no effect and 4 denoting maximum severity, and extent, with 0 denoting no appearance and 4 denoting full involvement. The results were calculated as the product of severity and extent of each feature, ranging from 0 to 16 , and added to yield the total lung damage score, ranging from 0 to 48 .

\section{Ultrastructural lung damage}

To obtain a stratified random sample, three $2 \times 2 \times 2 \mathrm{~mm}$ slices were cut from different segments of the left lung. Ultrathin sections from selected areas were examined and micrographed in a JEOL electron microscope (JSM-6100 F; Tokyo, Japan). In each image ( $n=15 /$ animal), the following structures were analyzed: 1 ) type II epithelial cell damage; 2) alveolar-capillary membrane damage; and 3) organelle injury. A procedure similar to that adopted for total lung damage score calculation was used to compute the ultrastructural damage score.

\section{Blood bacterial counts}

Blood samples $(20 \mu \mathrm{L})$ were seeded in Petri dishes with Tryptic Soy Agar growth medium (Fluka Analytical, St Louis, MO, USA). Manual counts of colony forming units (CFU) were performed after $24 \mathrm{~h}$ of incubation at $37^{\circ} \mathrm{C}$.

\section{Biomarkers of inflammation, alveolar stretch, and cell damage}

Quantitative real-time reverse transcription polymerase chain reaction (PCR) was performed to measure biomarkers associated with inflammation (interleukin [IL]-6 and cytokine-induced neutrophil chemoattractant [CINC1]), type II alveolar cell mechanotransduction (surfactant protein-D [SP-D]), endothelial cell injury (angiopoietin [Ang]-2), and alveolar stretch (amphiregulin). The primers used are described in the online supplement (Additional file 1: Table S1). Central slices of the right lung were cut, collected in cryotubes, flash-frozen by immersion in liquid nitrogen, and stored at $-80{ }^{\circ} \mathrm{C}$. Total RNA was extracted from frozen tissues using the RNeasy Plus Mini Kit (Qiagen, Hilden, Germany), following the manufacturer's recommendations. RNA concentrations were measured by spectrophotometry in a Nanodrop ND-1000 system (ThermoScientific, Wilmington, DE, USA). First-strand cDNA was synthesized from total RNA using a Quantitec reverse transcription kit (Qiagen, Hilden, Germany). Relative mRNA levels were measured with a SYBR green detection system in an ABI 7500 real-time PCR system (Applied Biosystems, Foster City, California, USA). Samples were run in triplicate. For each sample, the expression of each gene was normalized to the acidic ribosomal phosphoprotein P0 (36B4) housekeeping gene [19] and expressed as fold change relative to respective $\mathrm{NV}$ animals, using the $2^{-\Delta \Delta} \mathrm{Ct}$ method, where $\Delta \mathrm{Ct}=\mathrm{Ct}_{\text {refer- }}$ ence gene $-\mathrm{Ct}_{\text {target gene }}[20]$.

\section{Statistical analysis}

Sample size calculation was based on effect estimates obtained from previous studies in rodents using similar ventilator settings [8]. A sample size of eight animals per group would provide the appropriate power $(1-\beta=0.8)$ to identify significant $(\alpha=0.05)$ differences in respiratory system elastance between VCV and variable ventilation, taking into account an effect size $\mathrm{d}=1.38$, a two-sided test, and a sample size ratio $=1$ (G*Power 3.1.9.2, University of Düsseldorf, Düsseldorf, Germany).

The Kolmogorov-Smirnov test with Lilliefors correction was used to assess the normality of data, whereas the Levene median test was used to evaluate the homogeneity of variances. For the pneumonia model, the Student $t$-test and Mann-Whitney $U$ test were used for comparisons of parametric and nonparametric data respectively.

For comparison between conventional and variable ventilations, two-way analysis of variance (ANOVA) followed by Holm-Sidak multiple comparisons was used for analyses of lung mechanics, blood gas exchange, and postmortem parameters (lung damage score, ultrastructural damage score, and blood bacterial counts). Molecular biology analyses were performed using the Kruskal-Wallis test followed by Dunn multiple comparisons within the SAL (NV, VCV, VV) and PA (NV, VCV, VV) groups. Parametric data were expressed as mean \pm standard deviation (SD), and nonparametric data, as median (interquartile range). All tests were performed using the GraphPad Prism v6.01 statistical software package (GraphPad Software, La Jolla, California, USA). Significance was established at $p<0.05$.

\section{Results}

The characterization of the pneumonia model is presented in the online supplement (Additional file 1: Fig. S1, Tables S1, S2, and S3). In PA animals, hemorrhagic areas are present (Additional file 1: Fig. S1), with perivascular edema, neutrophils in alveolar septa, and necrotizing vasculitis (Additional file 1: Table S2). Additionally, an intense inflammatory process characterized by increased cell counts in BALF and blood was observed in PA compared to healthy rats (Additional file 1: Table S3), thus leading to reduced oxygenation (Additional file 1: Table S1). Taken together, those alterations suggest that the pneumonia model was adequate.

MAP was stable throughout the experiment (Table 1). Both in SAL and PA, mean $\mathrm{V}_{\mathrm{T}}$ was comparable in $\mathrm{VV}$ and VCV, whereas CV was higher in VV (Table 1). Compared to $\mathrm{VCV}, \mathrm{VV}$ reduced $\mathrm{E}_{\mathrm{L}}$ and increased oxygenation in SAL and PA. 
Table 1 Respiratory and blood gas-exchange parameters at Baseline and End

\begin{tabular}{|c|c|c|c|c|c|}
\hline \multirow{2}{*}{ Parameter } & & \multicolumn{2}{|l|}{ SAL } & \multicolumn{2}{|l|}{ PA } \\
\hline & & VCV & W & VCV & $W$ \\
\hline \multirow[t]{2}{*}{ Mean $\mathrm{V}_{\mathrm{T}}(\mathrm{mL} / \mathrm{kg})$} & Baseline & $5.8 \pm 0.3$ & $6.0 \pm 0.1$ & $6.0 \pm 0.3$ & $5.9 \pm 0.4$ \\
\hline & End & $5.9 \pm 0.6$ & $6.2 \pm 0.3$ & $6.0 \pm 0.3$ & $6.2 \pm 0.4$ \\
\hline \multirow[t]{2}{*}{$C V$ of $V_{T}(\%)$} & Baseline & $2.5 \pm 0.8$ & $2.3 \pm 0.4$ & $1.9 \pm 0.9$ & $1.9 \pm 0.8$ \\
\hline & End & $1.7 \pm 1.0$ & $26.5 \pm 1.8^{* * * *}$ & $1.7 \pm 0.8$ & $26.6 \pm 1.2$ \#\#\#\# \\
\hline \multirow[t]{2}{*}{$\mathrm{E}_{\mathrm{L}}\left(\mathrm{cmH}_{2} \mathrm{O} / \mathrm{mL}\right)$} & Baseline & $3.6 \pm 0.5$ & $4.2 \pm 0.9$ & $3.9 \pm 0.6$ & $4.6 \pm 0.7$ \\
\hline & End & $4.1 \pm 0.5$ & $2.5 \pm 0.3^{* * * *}$ & $3.8 \pm 0.5$ & $2.7 \pm 0.2 \# \#$ \\
\hline \multirow[t]{2}{*}{$\mathrm{R}_{\mathrm{L}}\left(\mathrm{cmH}_{2} \mathrm{O} / \mathrm{mL} / \mathrm{s}\right)$} & Baseline & $0.19 \pm 0.03$ & $0.18 \pm 0.03$ & $0.30 \pm 0.07^{* *}$ & $0.31 \pm 0.10$ \\
\hline & End & $0.19 \pm 003$ & $0.16 \pm 0.01$ & $0.25 \pm 0.07$ & $0.27 \pm 0.10$ \\
\hline \multirow[t]{2}{*}{$\mathrm{pHa}$} & Baseline & $7.4 \pm 0.1$ & $7.4 \pm 0.0$ & $7.3 \pm 0.1$ & $7.3 \pm 0.1$ \\
\hline & End & $7.4 \pm 0.1$ & $7.4 \pm 0.0$ & $7.4 \pm 0.1$ & $7.4 \pm 0.0$ \\
\hline \multirow[t]{2}{*}{$\mathrm{PaO}_{2} / \mathrm{FiO}_{2}$} & Baseline & $372 \pm 126$ & $311 \pm 83$ & $260 \pm 59$ & $285 \pm 80$ \\
\hline & End & $292 \pm 78$ & $449 \pm 50^{* *}$ & $302 \pm 117$ & $454 \pm 59 \# \#$ \\
\hline \multirow[t]{2}{*}{$\mathrm{PaCO}_{2}(\mathrm{mmHg})$} & Baseline & $40.2 \pm 8.0$ & $39.6 \pm 6.0$ & $40.2 \pm 4.9$ & $42.9 \pm 11.1$ \\
\hline & End & $36.4 \pm 10.1$ & $33.9 \pm 7.3$ & $37.2 \pm 4.8$ & $36.5 \pm 8.8$ \\
\hline \multirow[t]{2}{*}{$\mathrm{HCO}_{3}(\mathrm{mEq} / \mathrm{L})$} & Baseline & $23.7 \pm 3.1$ & $24.0 \pm 2.5$ & $20.8 \pm 3.2$ & $20.8 \pm 3.2$ \\
\hline & End & $18.9 \pm 4.4$ & $20.0 \pm 4.4$ & $21.5 \pm 2.6$ & $21.5 \pm 2.6$ \\
\hline \multirow[t]{2}{*}{ MAP (mmHg) } & Baseline & $109 \pm 24$ & $99 \pm 12$ & $96 \pm 34$ & $110 \pm 27$ \\
\hline & End & $99 \pm 15$ & $110 \pm 22$ & $97 \pm 28$ & $112 \pm 28$ \\
\hline
\end{tabular}

Values are mean \pm standard deviation (SD) of 8 animals in each group

Abbreviations: SAL-VCV rats administered intratracheal saline and ventilated with volume-controlled ventilation, $S A L-V V$ rats administered intratracheal saline and ventilated with variable ventilation, $P A-V C V$ rats administered intratracheal $P$ seudomonas aeruginosa and ventilated with volume-controlled ventilation, $P A-V V$ rats administered intratracheal Pseudomonas aeruginosa and ventilated with variable ventilation, $V_{T}$ tidal volume, $C V$ coefficient of variation, $E_{L} L$ dynamic lung elastance, $R_{, L}$ lung resistance, $\mathrm{pHa}$ arterial $\mathrm{pH}, \mathrm{PaCO}_{2}$ arterial carbon dioxide partial pressure, $\mathrm{PaO}_{2} / \mathrm{FiO}_{2}$ arterial oxygen partial pressure divided by fraction of oxygen inspired, $\mathrm{HCO}_{3}$ bicarbonate, MAP mean arterial pressure

Comparisons were performed using two-way repeated measures ANOVA followed by the Holm-Šídák post-hoc test $(p<0.05)$. ${ }^{* *} p<0.005 ;{ }^{* * * *} p<0.0001$ vs SALVCV. \#\#p $<0.01 ; \# \# \# p<0.0001$ vs PA-VCV

Light microscopy images of representative animals from each group are shown in Fig. 2. As depicted in Table 2, compared to VCV, VV yielded less perivascular edema, septum neutrophils, and necrotizing vasculitis during PA, but not SAL. Additionally, there was less damage to the lung ultrastructure in VV compared to VCV.

In SAL, IL-6 expression was lower in VV compared to VCV (Additional file 1: Fig. S2). Moreover, SP-D expression was higher in VV than NV (Additional file 1: Fig. S2).

In PA, gene expressions of IL-6, CINC-1, and amphiregulin were higher in $\mathrm{VCV}$, but not in $\mathrm{VV}$, compared to NV. Furthermore, Ang-2 expression was lower after VV compared to NV (Fig. 3).

Blood CFU counts were higher in PA than SAL animals (Fig. 4), but values did not differ significantly between VCV and VV, irrespective of group.

\section{Discussion}

The main findings of the present study were: 1 ) in both SAL and PA, VV improved $\mathrm{E}_{\mathrm{L}}$ and oxygenation compared to VCV; 2) in SAL, VV was associated with lower IL-6 expression in lung tissue than VCV and increased surfactant protein-D expression compared to $\mathrm{NV}$; 3) in $\mathrm{PA}, \mathrm{VV}$ reduced perivascular edema, septum neutrophils, necrotizing vasculitis, and ultrastructural lung damage, with no significant difference in blood CFU counts, compared to VCV. Furthermore, mRNA expression of amphiregulin, IL-6 and CINC-1 was higher in VCV, while expression of Ang-2 was lower in VV compared to NV.

A major strength of the present study is that the pathogen chosen, Pseudomonas aeruginosa, is a common cause of both community and hospital-acquired pneumonia [21], which is associated with considerable morbidity and mortality [22]. In addition, different aspects of the pneumonia model, including functional, structural, and ultrastructural features, the inflammatory response, and the potential for translocation of bacteria during mechanical ventilation, were characterized in detail (Additional file 1: Figure S1, Tables S1, S2, and S3). We chose a $\mathrm{CV}$ of $30 \%$ in $\mathrm{V}_{\mathrm{T}}$ because this level of variability has been shown to improve lung function $[8,23]$ and reduce lung damage in direct ARDS in rats [8], as well as other species [9, 24-27]. Additionally, controls with i.t. saline instillation were included to allow identification of possible effects that might be specific to the pneumonia model and to exclude the possibility of contamination 

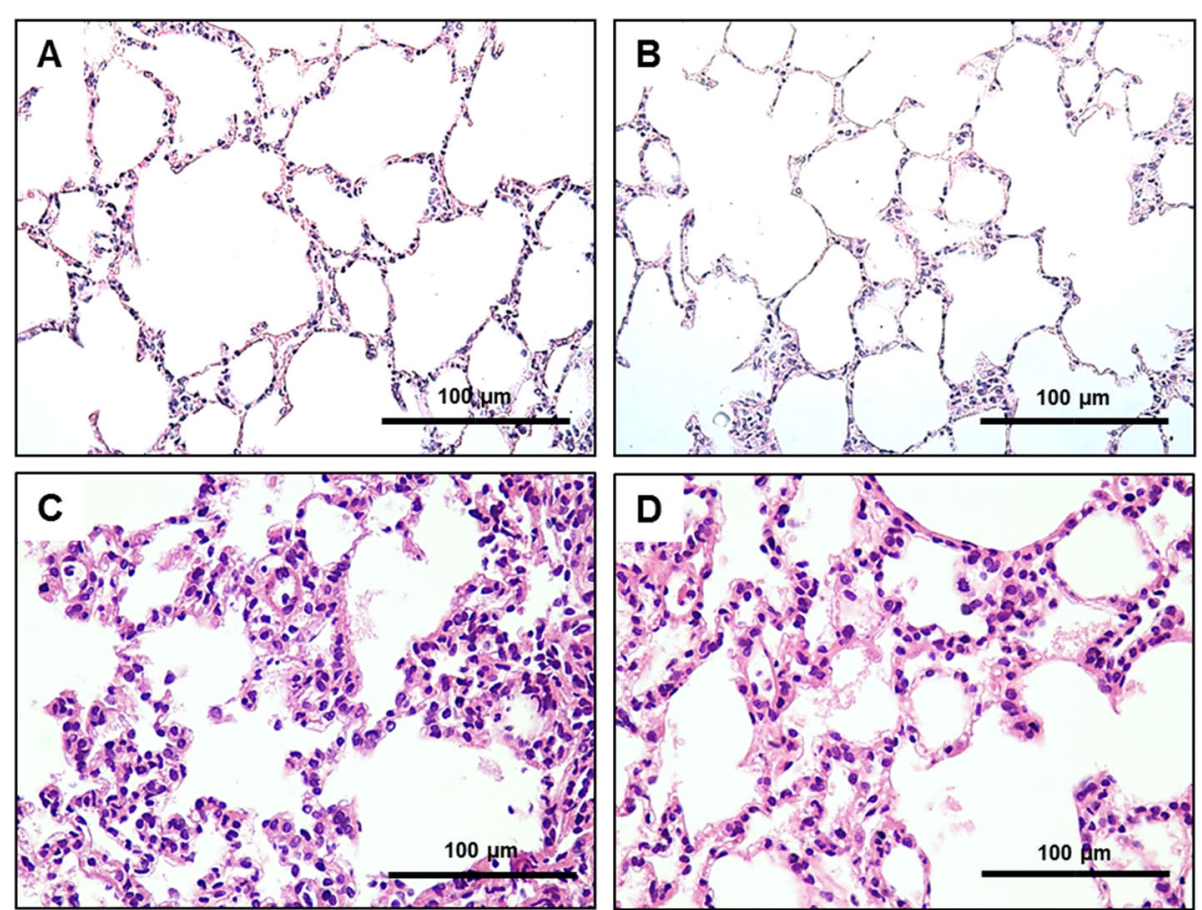

Fig. 2 Representative light microscopy images. a SAL-VCV: rats administered intratracheal saline and ventilated with volume-controlled ventilation. b SAL-W = rats administered intratracheal saline and ventilated with variable ventilation. $\mathbf{c}$ PA-VCV $=$ rats administered intratracheal Pseudomonas aeruginosa and ventilated with volume-controlled ventilation. $\mathbf{d}$ PA-W $=$ rats administered intratracheal Pseudomonas aeruginosa and ventilated with variable ventilation. Original magnification: $\times 400$. Scale bar is $100 \mu \mathrm{m}$

due to manipulation of the peripheral blood samples. To the best of our knowledge, this was the first study to evaluate variable ventilation in experimental pneumonia.

Our observation that VV improved oxygenation in both PA and SAL, as compared to VCV, can be explained by different factors. First, VV has been shown to promote effective recruitment of atelectatic lungs $[10,28,29]$, which seems to be accompanied by redistribution of perfusion to recruited areas [27], improving ventilation/perfusion matching in both SAL and PA. Second, variable $V_{T}$ is able to increase the release of surfactant $[30,31]$, which could reduce surface

Table 2 Lung damage score

\begin{tabular}{|c|c|c|c|c|}
\hline \multirow[b]{2}{*}{ Features } & \multicolumn{2}{|l|}{ SAL } & \multicolumn{2}{|l|}{ PA } \\
\hline & $\overline{V C V}$ & W & $\overline{V C V}$ & W \\
\hline \multicolumn{5}{|l|}{ Light microscopy } \\
\hline Perivascular edema [0-16] & $1.5[1.0-2.0]$ & $1.0[0.0-2.0]$ & $6.0[4.5-6.0]^{*}$ & $2.5[2.0-3.75] \#, \neq$ \\
\hline Septal neutrophils [0-16] & $0.0[0.0-0.0]$ & $0.0[0.0-0.0]$ & $5.0[3.3-6.0]^{*}$ & $2.0[1.0-4.0] \#, \ddagger$ \\
\hline Necrotizing vasculitis [0-16] & $1.5[0.0-2.0]$ & $1.0[1.0-1.0]$ & $6.0[6.0-6.0]^{*}$ & $3.0[2.0-5.5] \#, \neq$ \\
\hline Total lung damage score [0-48] & $2.5[2.0-3.8]$ & $2.0[1.0-3.0]$ & $16[15-18]^{*}$ & $8.0[5.5-11.3] \#, \neq$ \\
\hline \multicolumn{5}{|l|}{ Transmission electron microscopy } \\
\hline Type 2 epithelial cell damage [0-16] & $3[2-3]$ & $2[1-2]$ & $6[4-9]$ & $5[5-6]$ \\
\hline Alveolar capillary membrane damage [0-16] & $2[2-3]$ & $1[1-2]$ & $9[4-12]^{*}$ & $5[5-5]$ \\
\hline Organelle injury [0-16] & $2[2-3]$ & $1[1-2]$ & $6[6-9]^{* *}$ & $6[4-6]$ \\
\hline Total ultrastructural damage score [0-48] & $7[6-9]$ & $5[3-5]$ & $24[14-27]^{* * *}$ & 16 [14-17]\#\#, キ \\
\hline
\end{tabular}

Values are median and interquartile range [25-75\%] of 8 animals in each group

Abbreviations: SAL-VCV rats administered intratracheal saline and ventilated with volume-controlled ventilation, SAL-VV rats administered intratracheal saline and ventilated with variable ventilation, $P A-V C V$ rats administered intratracheal Pseudomonas aeruginosa and ventilated with volume-controlled ventilation, $P A-V V$ rats administered intratracheal Pseudomonas aeruginosa and ventilated with variable ventilation

Comparisons were performed by two-way ANOVA followed by the Holm-Šídák multiple comparison test $(p<0.05) .{ }^{*} p<0.05,{ }^{* *} p<0.01,{ }^{* * *} p<0.001$ significantly different from SAL-VCV. \#p $<0.05$, \#\#p $<0.01$ significantly different from SAL-VV. $\neq p<0.05$ significantly different from PA-VCV 

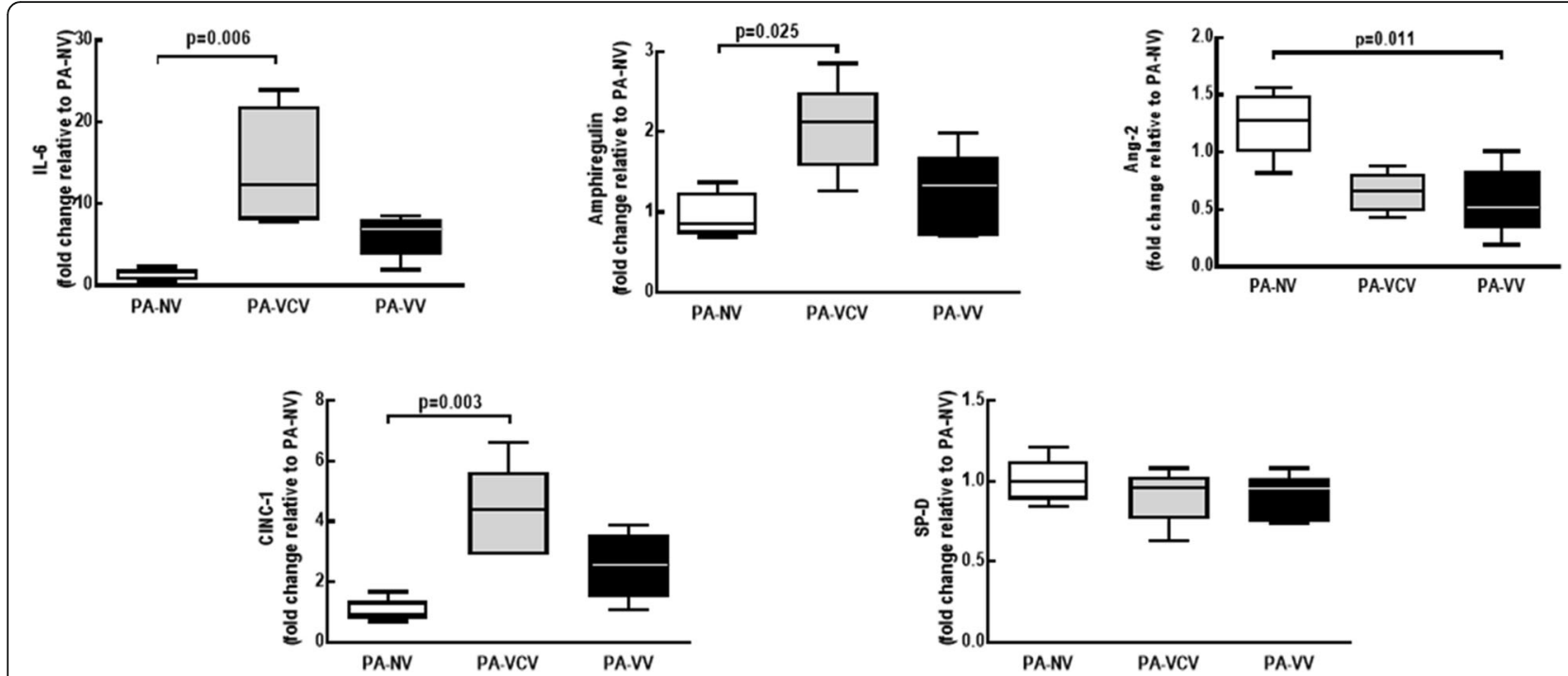

Fig. 3 Expression of biological markers. Real-time polymerase chain reaction analysis of biological markers associated with inflammation (IL-6 and CINC-1), alveolar overdistension (amphiregulin), endothelial cell damage (angiopoietin [Ang]-2), and epithelial cell mechanotransduction (surfactant protein [SP]-D). Relative gene expression was calculated as the ratio of average gene expression levels compared with the reference gene (36B4) and expressed as fold change relative to non-ventilated (NV) animals with pneumonia (PA). SAL-VCV: rats administered intratracheal saline and ventilated with volume-controlled ventilation; SAL-W = rats administered intratracheal saline and ventilated with variable ventilation; PA-VCV $=$ rats administered intratracheal Pseudomonas aeruginosa and ventilated with volume-controlled ventilation; PA-W = rats administered intratracheal Pseudomonas aeruginosa and ventilated with variable ventilation. Values represent medians and whiskers represent the 10-90 percentile range of 8 animals in each group. Kruskal-Wallis test followed by Dunn's test for comparisons among groups $(p<0.05)$

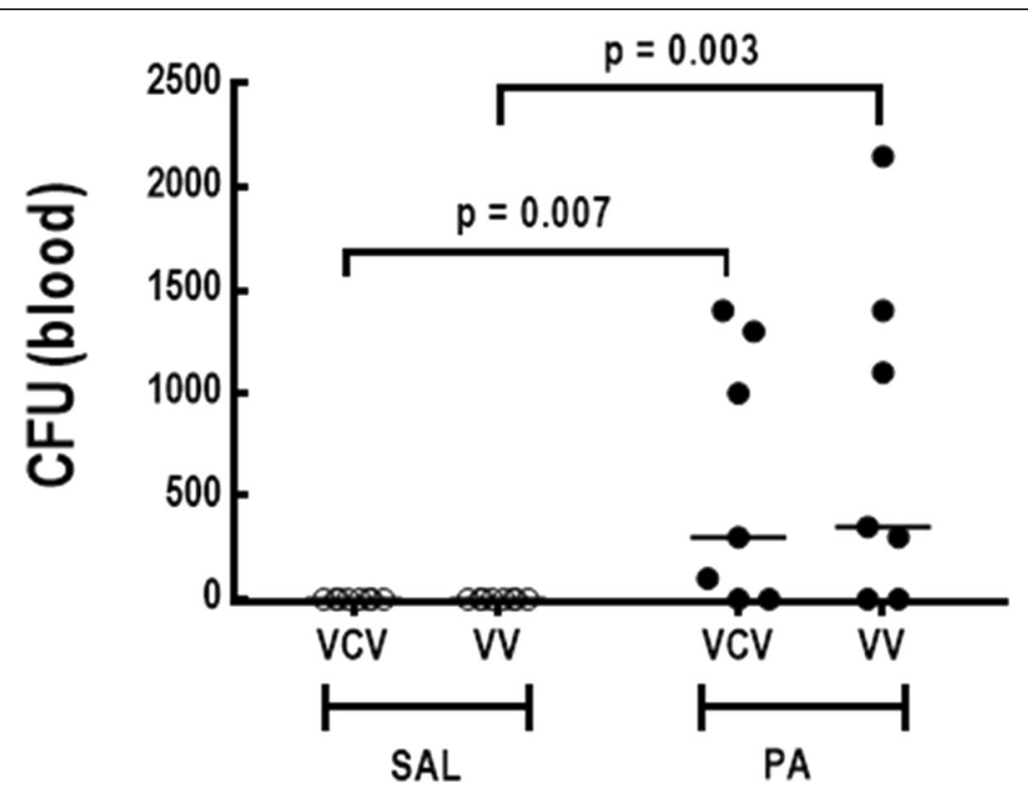

Fig. 4 Blood bacterial counts. Each symbol represents individual animals. Black lines are median values of 8 animals in each group. SAL-VCV: rats administered intratracheal saline and ventilated with volume-controlled ventilation; SAL-W = rats administered intratracheal saline and ventilated with variable ventilation; PA-VCV = rats administered intratracheal Pseudomonas aeruginosa and ventilated with volume-controlled ventilation; PA-W $=$ rats administered intratracheal Pseudomonas aeruginosa and ventilated with variable ventilation. Comparisons were performed using two-way ANOVA followed by the Holm-Sidák post-hoc test $(p<0.05)$ 
tension and further stabilize the lungs, thus improving gas exchange in SAL.

The hypothesis that VV would recruit lungs compared to $\mathrm{VCV}$ is supported by the decrease in $\mathrm{E}_{\mathrm{L}}$. The improvement in $\mathrm{E}_{\mathrm{L}}$ could partly explain the finding that, in PA, VV led to less perivascular edema, septum neutrophils, and necrotizing vasculitis, which are hallmarks not only of pneumonia [18], but also of VILI [32]. When recruitment occurs, $V_{T}$ is distributed across a larger lung surface area, resulting in decreased regional stress and strain, with less mechanotransduction and biotrauma [33].

This interpretation is supported by the fact that VCV, but not VV, increased the expression of amphiregulin, a marker of pulmonary stretch [34]; IL-6 and CINC-1, which are inflammatory mediators of VILI [35]; and Ang-2, a marker of endothelial integrity [36].

In SAL, VV increased SP-D expression compared to $\mathrm{VCV}$, suggesting that surfactant production was triggered. SP-D plays a central role in pulmonary host defense [37] and migration of peripheral monocyte/macrophages into the lungs [38]. This might explain the reduction in IL-6 with increased SP-D expression in SAL groups $(r=-0.81$, $p=0.007)$. In PA, however, SP-D expression did not differ significantly between $\mathrm{VV}$ and $\mathrm{VCV}$. A possible explanation for this difference is that the increased inflammatory response of type 2 epithelial cells due to infection by Pseudomonas aeruginosa [39] impaired surfactant production.

We observed that i.t. instillation of Pseudomonas aeruginosa increased blood CFU counts in PA compared to SAL. However, among PA animals, CFU blood counts were comparable between VV and VCV. There are different possible explanations for the lack of bacterial translocation during VV in PA. First, the mechanical stress of isolated respiratory cycles may not have exceeded the plasto-elasticity limit of the lung tissue [40], thus preserving the integrity of the alveolar-capillary membrane [41]. Second, lung recruitment likely occurred, reducing volutrauma and atelectrauma, which are intrinsically involved in bacterial translocation during pneumonia [13]. Similar findings have been observed in which PEEP might reduce the risk of ventilation-induced dissemination of bacteria and inflammatory mediators during pneumonia [42, 43].

\section{Possible clinical implications of study findings}

The present study expands the notion that VV is associated with beneficial effects on gas exchange and lung protection in respiratory failure. Since pneumonia is one of the major risk factors for ARDS development [2] and these patients frequently require mechanical ventilation, VV might represent a valuable strategy to improve pulmonary function and reduce lung damage without promoting further injury or bacterial translocation to the blood stream. Furthermore, in patients without lung injury, VV might be useful to prevent deterioration of lung function and increases in inflammatory markers, which could lead to further pulmonary complications. These issues warrant investigation in future experimental and clinical studies.

\section{Limitations}

Some limitations of this study must be noted. First, pneumonia was induced by i.t. instillation of Pseudomonas aeruginosa, and our results cannot be extrapolated to other types of pulmonary infection. Nevertheless, in a 10year retrospective study [21], $45.8 \%$ of patients had nosocomial-acquired pneumonia caused by Pseudomonas aeruginosa. Furthermore, lungs infected by other pathogens might also benefit from VV-induced responses, e.g., increased production of surfactant. Second, the data presented herein refer to the application of variable ventilation during controlled mechanical ventilation, not assisted ventilation, which might have yielded different results. Third, unlike in clinical settings, PEEP, respiratory rate, and $\mathrm{FiO}_{2}$ were kept constant. However, as the main objective was to evaluate $\mathrm{VV}$, confounding factors resulting from changes in ventilator settings were excluded. In this line, the level of PEEP used in the current study, while often used in rats, may not be directly extrapolated to the clinical setting. Nevertheless, it has been estimated that values of PEEP in rats should be multiplied by a factor of 2 to 2.5 [44], when comparing with humans. In our study, this corresponds to 10 to $12.5 \mathrm{cmH}_{2} \mathrm{O}$, i.e., a moderate to high PEEP value in humans. Fourth, the observation time was relatively short ( $2 \mathrm{~h}$ of mechanical ventilation), precluding extrapolation of the findings to longer periods of ventilation. Finally, protein levels of biomarkers of VILI were not determined. Instead, we chose to assess expression of biomarker mRNA, because an experimental period of $2 \mathrm{~h}$ might not be sufficient to detect differences in protein levels [45-48].

\section{Conclusions}

In the rat model of Pseudomonas aeruginosa pneumonia used herein, VV improved pulmonary function and reduced lung damage, without increasing bacterial translocation, compared to VCV.

\section{Additional file}

Additional file 1: Online Supplement. (DOCX 1309 kb)

\section{Abbreviations}

$(\dot{V} \cdot)$ : Airflow; 36B4: Acidic ribosomal phosphoprotein P0; Ang-2: Angiopoietin; ANOVA: Analysis of variance; ARDS: Acute respiratory distress syndrome; CFU: Blood colony-forming-unit; CINC: Cytokine-induced neutrophil chemoattractant; $\mathrm{CV}$ : Coefficient of variation; $\mathrm{E}_{\mathrm{L}}$ : Lung elastance; $\mathrm{FiO}_{2}$ : Fraction of inspired oxygen; i.v.: Intravenous; IL: Interleukin; MAP: Mean arterial pressure; NV: Non-ventilated; PA: Pseudomonas aeruginosa; Paw: Airway pressure; PCR: Polymerase chain reaction; PEEP: Positive end-expiratory pressure; Pes: Esophageal pressure; $R_{L}$ : Lung resistance; SAL: Saline; SD: Standard 
deviation; SP: Surfactant protein; VCV: Volume-controlled ventilation; VILI: Ventilator-induced lung injury; $V_{T}$ : Tidal volume; $\mathrm{W}$ : Variable volumecontrolled ventilation

\section{Acknowledgements}

We express our gratitude to Mr. Andre Benedito da Silva for animal care, Mrs. Ana Lucia Neves da Silva for her help with microscopy, Mrs. Moira Elizabeth Schottler and Mr. Filippe Vasconcellos for their assistance in editing the manuscript.

\section{Funding}

This study was supported by the Brazilian Council for Scientific and Technological Development (CNPq), the Rio de Janeiro State Research Foundation (FAPERJ), the Department of Science and Technology (DECIT)/Brazilian Ministry of Health, and the Coordination for the Improvement of Higher Education Personnel (CAPES).

\section{Availability of data and materials}

The datasets during and/or analyzed during the current study available from the corresponding author on reasonable request.

\section{Authors' contributions}

RFM participated in the design of the study, carried out the experiments, performed data analyses and drafted the manuscript; RSS and CSS contributed to the study design, carried out the experiments; NNR, CLS, JK, CAMS and CLH carried out the experiments, and performed data analyses; CFGA, ARS, HCFN and PO provided expert assistance during experiments, and helped draft the manuscript; CLS and MMM carried out the molecular biology analyses and contributed to the manuscript; VMS and VLC performed the histological analyses and helped draft the manuscript; PP and contributed to the study design, supervised the entire project and helped write the manuscript; PRMR and PLS contributed to the study design, supervised the experimental work and statistical analysis, wrote the manuscript and supervised the entire project. All authors read and approved the final manuscript.

\section{Competing interests}

The authors declare they have no competing interests.

\section{Consent for publication}

Not applicable.

\section{Ethics approval and consent to participate}

This study was approved by the Animal Care Committee of the Health Sciences Center, Federal University of Rio de Janeiro (CEUA 145/13), and registered with the Brazilian National Council for Animal Experimentation Control. All animals received humane care in compliance with the "Principles of Laboratory Animal Care" formulated by the National Society for Medical Research and the U.S. National Academy of Sciences Guide for the Care and Use of Laboratory Animals.

\section{Author details}

'Laboratory of Pulmonary Investigation, Carlos Chagas Filho Biophysics Institute, Federal University of Rio de Janeiro, Av. Carlos Chagas Filho, s/n, Bloco G-014, Ilha do Fundão, 21941-902 Rio de Janeiro, RJ, Brazil. '2Laboratory of Cellular and Molecular Physiology, Carlos Chagas Filho Biophysics Institute, Carlos Chagas Filho Biophysics Institute, Federal University of Rio de Janeiro, Av. Carlos Chagas Filho, s/n, Bloco G2-048, Ilha do Fundão, 21941-902 Rio de Janeiro, RJ, Brazil. ${ }^{3}$ Laboratory of Clinical Bacteriology and Immunology, Federal University of Rio de Janeiro, Rio de Janeiro, RJ, Brazil. ${ }^{4}$ Carlos Chagas Filho Biophysics Institute, Carlos Chagas Filho Biophysics Institute, Federal University of Rio de Janeiro, Av. Carlos Chagas Filho, s/n, Bloco G2-048, Ilha do Fundão, 21941-902 Rio de Janeiro, RJ, Brazil. ${ }^{5}$ Laboratory of Immunopharmacology, Oswaldo Cruz Institute - Fiocruz, Rio de Janeiro, RJ, Brazil. ${ }^{6}$ Department of Pathology, University of São Paulo, Av. Doutor Arnaldo, 455, 01246-903 São Paulo, SP, Brazil. ${ }^{7}$ Pulmonary Engineering Group, Department of Anesthesiology and Intensive Care Therapy, University Hospital Carl Gustav Carus, Dresden University of Technology, Fetschertsrasse 74, 01307 Dresden, Germany. ${ }^{8}$ IRCCS AOU San Martino-IST, Department of Surgical Sciences and Integrated Diagnostics, University of Genoa, Largo Rosanna Benzi 8, 16132 Genoa, Italy. 'Laboratory of Pulmonary Investigation, Centro de Ciências da Saúde, Carlos Chagas Filho Biophysics Institute,
Federal University of Rio de Janeiro, Avenida Carlos Chagas Filho, s/n, Bloco G-014, Ilha do Fundão, 21941-902 Rio de Janeiro, RJ, Brazil.

Received: 23 September 2016 Accepted: 22 November 2016 Published online: 25 November 2016

\section{References}

1. Herkel T, Uvizl R, Doubravska L, Adamus M, Gabrhelik T, Htoutou Sedlakova M, Kolar M, Hanulik V, Pudova V, Langova K, et al.: Epidemiology of hospitalacquired pneumonia: Results of a Central European multicenter, prospective, observational study compared with data from the European region. Biomedical papers of the Medical Faculty of the University Palacky, Olomouc, Czechoslovakia 2016

2. Bellani G, Laffey JG, Pham T, Fan E, Brochard L, Esteban A, Gattinoni L, van Haren F, Larsson A, McAuley DF, et al. Epidemiology, patterns of care, and mortality for patients with acute respiratory distress syndrome in intensive care units in 50 countries. JAMA. 2016;315:788-800.

3. Sweeney RM, McAuley DF: Acute respiratory distress syndrome. Lancet 2016.

4. Dhanireddy S, Altemeier WA, Matute-Bello G, O'Mahony DS, Glenny RW, Martin TR, Liles WC. Mechanical ventilation induces inflammation, lung injury, and extra-pulmonary organ dysfunction in experimental pneumonia. Lab investig j tech meths pathol. 2006;86:790-9.

5. Terragni PP, Del Sorbo L, Mascia L, Urbino R, Martin EL, Birocco A, Faggiano C, Quintel M, Gattinoni L, Ranieri VM. Tidal volume lower than $6 \mathrm{ml} / \mathrm{kg}$ enhances lung protection: role of extracorporeal carbon dioxide removal. Anesthesiology. 2009:111:826-35.

6. Wolthuis EK, Vlaar AP, Choi G, Roelofs JJ, Juffermans NP, Schultz MJ. Mechanical ventilation using non-injurious ventilation settings causes lung injury in the absence of pre-existing lung injury in healthy mice. Crit care. 2009;13:R1.

7. Spieth PM, Guldner A, Uhlig C, Bluth T, Kiss T, Schultz MJ, Pelosi P, Koch T, Gama De Abreu M. Variable versus conventional lung protective mechanical ventilation during open abdominal surgery: study protocol for a randomized controlled trial. Trials. 2014;15:155

8. Samary CS, Moraes L, Santos CL, Huhle R, Santos RS, Ornellas DS, Felix NS, Capelozzi VL, Schanaider A, Pelosi P, et al. Lung functional and biologic responses to variable ventilation in experimental pulmonary and extrapulmonary acute respiratory distress syndrome. Crit care med. 2016:44:e553-62.

9. Berry CA, Suki B, Polglase GR, Pillow JJ. Variable ventilation enhances ventilation without exacerbating injury in preterm lambs with respiratory distress syndrome. Pediatr res. 2012;72:384-92.

10. Graham MR, Gulati H, Kha L, Girling LG, Goertzen A, Mutch WA. Resolution of pulmonary edema with variable mechanical ventilation in a porcine model of acute lung injury. Can j anaesth j can d'anesth. 2011;58:740-50.

11. Goncalves-De-Albuquerque CF, Silva AR, Burth P, Rocco PR, Castro-Faria MV, Castro-Faria-Neto HC. Possible mechanisms of pseudomonas aeruginosaassociated lung disease. Int j med microbiol IJMM. 2016;306:20-8.

12. Lin $\mathrm{CY}$, Zhang $\mathrm{H}$, Cheng $\mathrm{KC}$, Slutsky AS. Mechanical ventilation may increase susceptibility to the development of bacteremia. Crit care med. 2003;31:1429-34.

13. Lachmann RA, van Kaam AH, Haitsma JJ, Lachmann B. High positive endexpiratory pressure levels promote bacterial translocation in experimental pneumonia. Intensive care med. 2007:33:1800-4.

14. Baydur A, Behrakis PK, Zin WA, Jaeger M, Milic-Emili J. A simple method for assessing the validity of the esophageal balloon technique. Am rev respir dis. 1982;126:788-91.

15. Huhle R, Spieth PM, Guldner A, Koch T, de Abreu MG. A new adaptive controller for volume-controlled mechanical ventilation in small animals. Exp lung res. 2014;40:186-97.

16. Henriques I, Padilha GA, Huhle R, Wierzchon C, Miranda PJ, Ramos IP, Rocha N, Cruz FF, Santos RS, de Oliveira MV, et al. Comparison between variable and conventional volume-controlled ventilation on cardiorespiratory parameters in experimental emphysema. Front physiol. 2016;7:277.

17. Silva PL, Moraes L, Santos RS, Samary C, Ramos MB, Santos CL, Morales MM, Capelozzi VL, Garcia CS, de Abreu MG, et al. Recruitment maneuvers modulate epithelial and endothelial cell response according to acute lung injury etiology. Crit care med. 2013;41:e256-65.

18. Mizgerd JP, Skerrett SJ. Animal models of human pneumonia. Am j physiol lung cell mol physiol. 2008;294:L387-98. 
19. Akamine R, Yamamoto T, Watanabe M, Yamazaki N, Kataoka M, Ishikawa M, Ooie T, Baba Y, Shinohara Y. Usefulness of the 5 ' region of the CDNA encoding acidic ribosomal phosphoprotein PO conserved among rats, mice, and humans as a standard probe for gene expression analysis in different tissues and animal species. J biochem biophys methods. 2007;70:481-6.

20. Schmittgen TD, Livak KJ. Analyzing real-time PCR data by the comparative C(T) method. Nat protoc. 2008;3:1101-8.

21. Yayan J, Ghebremedhin B, Rasche K. Antibiotic resistance of pseudomonas aeruginosa in pneumonia at a single university hospital center in germany over a 10-year period. Plos one. 2015;10:e0139836.

22. Micek ST, Wunderink RG, Kollef MH, Chen C, Rello J, Chastre J, Antonelli M, Welte T, Clair B, Ostermann $\mathrm{H}$, et al. An international multicenter retrospective study of pseudomonas aeruginosa nosocomial pneumonia: impact of multidrug resistance. Crit care. 2015;19:219.

23. Kiss T, Silva PL, Huhle R, Moraes L, Santos RS, Felix NS, Santos CL, Morales MM, Capelozzi VL, Kasper M, et al. Comparison of different degrees of variability in tidal volume to prevent deterioration of respiratory system elastance in experimental acute lung inflammation. Br j anaesth. 2016;116:708-15.

24. Spieth PM, Carvalho AR, Guldner A, Kasper M, Schubert R, Carvalho NC, Beda A, Dassow C, Uhlig S, Koch T, et al. Pressure support improves oxygenation and lung protection compared to pressure-controlled ventilation and is further improved by random variation of pressure support. Crit care med. 2011;39:746-55.

25. Carvalho AR, Spieth PM, Guldner A, Cuevas M, Carvalho NC, Beda A, Spieth S, Stroczynski C, Wiedemann B, Koch T, et al. Distribution of regional lung aeration and perfusion during conventional and noisy pressure support ventilation in experimental lung injury. J appl physiol. 2011;110:1083-92.

26. Spieth PM, Carvalho AR, Guldner A, Pelosi P, Kirichuk O, Koch T, de Abreu MG. Effects of different levels of pressure support variability in experimental lung injury. Anesthesiology. 2009;110:342-50.

27. Spieth PM, Carvalho AR, Pelosi P, Hoehn C, Meissner C, Kasper M, Hubler M, von Neindorff M, Dassow C, Barrenschee M, et al. Variable tidal volumes improve lung protective ventilation strategies in experimental lung injury. Am j respir crit care med. 2009;179:684-93.

28. Brewster JF, Graham MR, Mutch WA. Convexity, Jensen's inequality and benefits of noisy mechanical ventilation. J r soc interface $r$ society. 2005;2:393-6.

29. Bellardine $C L$, Hoffman AM, Tsai L, Ingenito EP, Arold SP, Lutchen KR, Suki $B$. Comparison of variable and conventional ventilation in a sheep saline lavage lung injury model. Crit care med. 2006;34:439-45.

30. Arold SP, Suki B, Alencar AM, Lutchen KR, Ingenito EP. Variable ventilation induces endogenous surfactant release in normal guinea pigs. Am j physiol lung cell mol physiol. 2003;285:L370-5.

31. Arold SP, Bartolak-Suki E, Suki B. Variable stretch pattern enhances surfactant secretion in alveolar type II cells in culture. Am j physiol lung cell mol physiol. 2009;296:L574-81.

32. Matute-Bello G, Downey G, Moore BB, Groshong SD, Matthay MA, Slutsky AS, Kuebler WM. An official American thoracic society workshop report: features and measurements of experimental acute lung injury in animals. Am j respir cell mol biol. 2011;44:725-38.

33. Fan E, Villar J, Slutsky AS. Novel approaches to minimize ventilator-induced lung injury. BMC med. 2013;11:85.

34. Yerrapureddy A, Tobias J, Margulies SS. Cyclic stretch magnitude and duration affect rat alveolar epithelial gene expression. Cell physiol biochem. 2010;25:113-22.

35. Ko YA, Yang MC, Huang HT, Hsu CM, Chen LW. NF-kappaB activation in myeloid cells mediates ventilator-induced lung injury. Respir res. 2013;14:69.

36. Zinter MS, Spicer A, Orwoll BO, Alkhouli M, Dvorak CC, Calfee CS, Matthay MA, Sapru A. Plasma angiopoietin-2 outperforms other markers of endothelial injury in prognosticating pediatric ARDS mortality. Am j physiol lung cell mol physiol. 2016;310:L224-31.

37. Hartl D, Griese M. Surfactant protein D in human lung diseases. Eur $j$ clin invest. 2006;36:423-35

38. King BA, Kingma PS. Surfactant protein D deficiency increases lung injury during endotoxemia. Am j respir cell mol biol. 2011;44:709-15.

39. Vanderbilt JN, Mager EM, Allen L, Sawa T, Wiener-Kronish J, Gonzalez R, Dobbs LG. CXC chemokines and their receptors are expressed in type ॥ cells and upregulated following lung injury. Am j respir cell mol biol. 2003;29:661-8

40. Suki B, Bates JH. Lung tissue mechanics as an emergent phenomenon. J appl physiol. 2011;110:1111-8.
41. Fu Z, Costello ML, Tsukimoto K, Prediletto R, Elliott AR, Mathieu-Costello O, West JB. High lung volume increases stress failure in pulmonary capillaries. J appl physiol. 1992;73:123-33.

42. Schortgen F, Bouadma L, Joly-Guillou ML, Ricard JD, Dreyfuss D, Saumon G. Infectious and inflammatory dissemination are affected by ventilation strategy in rats with unilateral pneumonia. Intensive care med. 2004;30:693-701.

43. Nahum A, Hoyt J, Schmitz L, Moody J, Shapiro R, Marini JJ. Effect of mechanical ventilation strategy on dissemination of intratracheally instilled escherichia coli in dogs. Crit care med. 1997;25:1733-43.

44. Thammanomai A, Hamakawa H, Bartolak-Suki E, Suki B. Combined effects of ventilation mode and positive end-expiratory pressure on mechanics, gas exchange and the epithelium in mice with acute lung injury. Plos one. 2013;8:e53934.

45. Silva PL, Cruz FF, Fujisaki LC, Oliveira GP, Samary CS, Ornellas DS, MaronGutierrez T, Rocha NN, Goldenberg R, Garcia CS, et al. Hypervolemia induces and potentiates lung damage after recruitment maneuver in a model of sepsis-induced acute lung injury. Crit care. 2010;14:R114.

46. Riva DR, Oliveira MB, Rzezinski AF, Rangel G, Capelozzi VL, Zin WA, Morales MM, Pelosi P, Rocco PR. Recruitment maneuver in pulmonary and extrapulmonary experimental acute lung injury. Crit care med. 2008:36:1900-8

47. Passaro CP, Silva PL, Rzezinski AF, Abrantes S, Santiago VR, Nardelli L, Santos RS, Barbosa CM, Morales MM, Zin WA, et al. Pulmonary lesion induced by low and high positive end-expiratory pressure levels during protective ventilation in experimental acute lung injury. Crit care med. 2009;37:1011-7.

48. Santiago VR, Rzezinski AF, Nardelli LM, Silva JD, Garcia CS, Maron-Gutierrez T, Ornellas DS, Morales MM, Capelozzi VL, Marini J, et al. Recruitment maneuver in experimental acute lung injury: the role of alveolar collapse and edema. Crit care med. 2010;38:2207-14.

\section{Submit your next manuscript to BioMed Central and we will help you at every step:}

- We accept pre-submission inquiries

- Our selector tool helps you to find the most relevant journal

- We provide round the clock customer support

- Convenient online submission

- Thorough peer review

- Inclusion in PubMed and all major indexing services

- Maximum visibility for your research

Submit your manuscript at www.biomedcentral.com/submit
Biomed Central 